\title{
МЕЖРЕГИОНАЛЬНАЯ МИГРАЦИЯ В РОССИИ: ВОЗРАСТНЫЕ ОСОБЕННОСТИ
}

\author{
ЛИЛИЯ КАРАЧУРИНА, НИКИТА МКРТЧЯН
}

\begin{abstract}
Статья посвящена анализу возрастной структуры внутренней миграции населения по регионам России. Базой для работы послужили данные о возрастном составе межрегиональных мигрантов 8 регионах России за 2011-2015 г2. в разрезе однолетних возрастных групп, а также о численности населения регионов России по однолетним группам. В анализе для группировки регионов применяли метод кластеризации (по показателю доли прибывиих/выбывших в отдельных возрастных группах к общему числу мигрантов) регионов методом к-средних с использованием программы SPSS. Как и 6 других странах, пик интенсивности миграџии приходится на молодые возраста, он связан с массовым получением высшего образования. Далее с увеличением возраста миграционная активность падает. Некоторые возрастные профили миграции содержат затем вторичный пик в ранних пожильх возрастах, сопряженных с выходом на пенсию, возможностями переезда на территории, более отвечающие запросам 50-60-летних людей, либо с возвратной миграцией. Анализ выявил значительные различия между российскими регионами по возрастному профилю межрегиональной миграции - как входящих потоков (прибытий), так и исходящих (выбытий). Основные отличительные признаки - степень выраженности молодежного пика, наличие иных возрастных пиков.
\end{abstract}

Ключевые слова: возраст, миграчия населения, межрегиональная миграчия, возрастной профиль, регионы России.

\section{ВВЕДЕНИЕ}

Миграция населения вносит весомый вклад в демографическое состояние регионов России. При этом, как и во всем мире, воздействие внутренней миграции, по меньшей мере, не уступает, а зачастую превосходит, влияние международной [Доклад... 2009: 21; Human Development... 2009: 21]. Оно определяется не только абсолютными масштабами притока и оттока людей, но и структурами потоков. В данной статье мы пытаемся показать, что на разные регионы страны миграция (структурой входящего и исходящего потоков) влияет поразному. В условиях постепенного эволюционного снижения межрегиональной дифференциации показателей рождаемости [Захаров, Иванова 1996; Население России... 2002: 47-50] это является важным фактором эволюции демографической ситуации в регионах.

\footnotetext{
ЛИЛИЯ БОРИСОВНА КАРАЧУРИНА (lkarachurina@hse.ru), НАЦИОНАЛЬНЫЙ ИССЛЕДОВАТЕЛЬСКИЙ УНИВЕРСИТЕТ «ВЫСШАЯ ШКОЛА ЭКОНОМИКИ», РОССИЯ.

НИКИТА ВЛАДИМИРОВИЧ МКРТЧЯН, НАЦИОНАЛЬНЫЙ ИССЛЕДОВАТЕЛЬСКИЙ УНИВЕРСИТЕТ ВЫСШАЯ ШКОЛА ЭКОНОМИКИ», РОССИЙСКАЯ АКАДЕМИЯ НАРОДНОГО ХОЗЯЙСТВА И ГОСУДАРСТВЕННОЙ СЛУЖБЫ, РОССИЯ.

СТАТЬЯ ПОДГОТОВЛЕНА ПО РЕЗУЛЬТАТАМ ИССЛЕДОВАТЕЛЬСКОГО ПРОЕКТА «ТЕНДЕНЦИИ ДЕМОГРАФИЧЕСКОГО РАЗВИТИЯ РОССИИ В 2005-2015 ГГ. В КОНТЕКСТЕ ДОЛГОВРЕМЕННЫХ ДЕМОГРАФИЧЕСКИХ ТРЕНДОВ», ВЫПОЛНЕННОГО В РАМКАХ ПРОГРАММЫ ФУНДАМЕНТАЛЬНЫХ ИССЛЕДОВАНИЙ НИУ ВШЭ В 2016 Г.
}

СТАТЬЯ ПОСТУПИЛА В РЕДАКЦИЮ В СЕНТЯБРЕ 2016 Г. 


\section{ИЗУЧЕННОСТЬ ПРОБЛЕМЫ}

Анализ возрастной структуры миграционных потоков разной направленности (международных, внутристрановых) и на разных иерархических уровнях (страны, регионов, муниципальных образований), а также вопросы взаимовлияния миграции и возрастных структур населения территорий выезда/вселения и наоборот - классическая тема демографических исследований. Как ни странно, однако, в России она до сих пор представлена фрагментарно. В частности, в 2000-2010-е годы появились исследования по внутренней учебной миграции на страновом [Варшавская, Чудиновских 2014; Замятина 2012; Катровский 1999; Флоринская, Рощина 2008; Чудиновских, Денисенко 2003] и региональном [Дементьева, Гиниятова 2012; Чихичин 2014; Эмбрехт 2011] уровнях, авторы которых используют в анализе демографический и геопространственный подходы. Работы Н.В. Мкртчяна и И.С. Кашницкого показывают, что миграционная активность в молодых возрастах многократно выше, чем во всех остальных, она проявляется как на уровне регионов (в частности выделяются регионы, привлекательные для студенческой миграции), так и на внутрирегиональном уровне [Мкртчян 2013; Кашницкий, Мкртчян, Лешуков 2016; Kashnitsky, Mkrtchhyan 2014]. Работы по миграции людей активных трудоспособных возрастов хотя и нередки, но до сих пор подходят к изучению миграций населения почти исключительно с ресурсных позиций («трудовые ресурсы», «производительные силы» и др.), не обременяя себя разноплановостью и подходом с позиции «жизненного пути». Миграция пожилых по-прежнему остается вне исследовательского фокуса в России. Редкие и давние работы по этой теме [Моисеенко, Чудиновских 2000; Тарасова 2013; Гридасов, Захарова, Балуева 2011] показывают, что Россия относится скорее к таким странам, где пик миграционной активности в пожилых возрастах на страновом уровне почти не заметен и не удостоен отдельного изучения в этой связи. В комплексной работе Г.В. Рахмановой [1994] впервые для России были построены и проанализированы возрастные профили миграции для страны и ее экономических районов. В исследовании Н.В. Мкртчяна [2014] сделана попытка проследить на региональном уровне влияние миграционного прироста в возрастах до и после 40 лет на возрастную структуру населения, а в исследовании С.П. Ермакова и С.Ю. Никитиной [2015] - смоделировать возрастные особенности миграции в России. В целом, однако, необходимо констатировать наличие очень незначительного числа отечественных работ, анализирующих возрастные особенности миграционных потоков.

Между тем западные исследователи давно и глубоко занимаются подобной тематикой. Одной из первых работ, показывающих возрастную специфику миграционных потоков в США, стало исследование Д. Питтенгера [Pittenger 1974]. На примере нескольких ключевых территорий было выявлено, что центральные города, пригороды, сельские территории имеют свойственные только им возрастные особенности миграции. А. Роджерс и Л. Кастро [Rogers, Castro 1981, 1986] обнаружили, что, хотя уровень миграции существенно различается между странами, формы возрастных кривых миграции схожи для многих стран. На рисунке 1 представлен стандартный возрастной профиль миграции. Самая интенсивная миграция свойственна молодым возрастам, когда люди переезжают для обучения, затем для старта трудовой деятельности, создания семьи. Далее с увеличением возраста миграционная активность падает по мере наступления стабильности в жизни человека: появления собственности, достижения детьми школьного возраста и обучения в 
школе. Некоторые возрастные профили миграции содержат затем вторичный пик в ранних пожилых возрастах, связанный с взрослением детей, выходом на пенсию, возможностями переезда на территории, более отвечающие запросам к качеству жизни 50-60-летних людей.

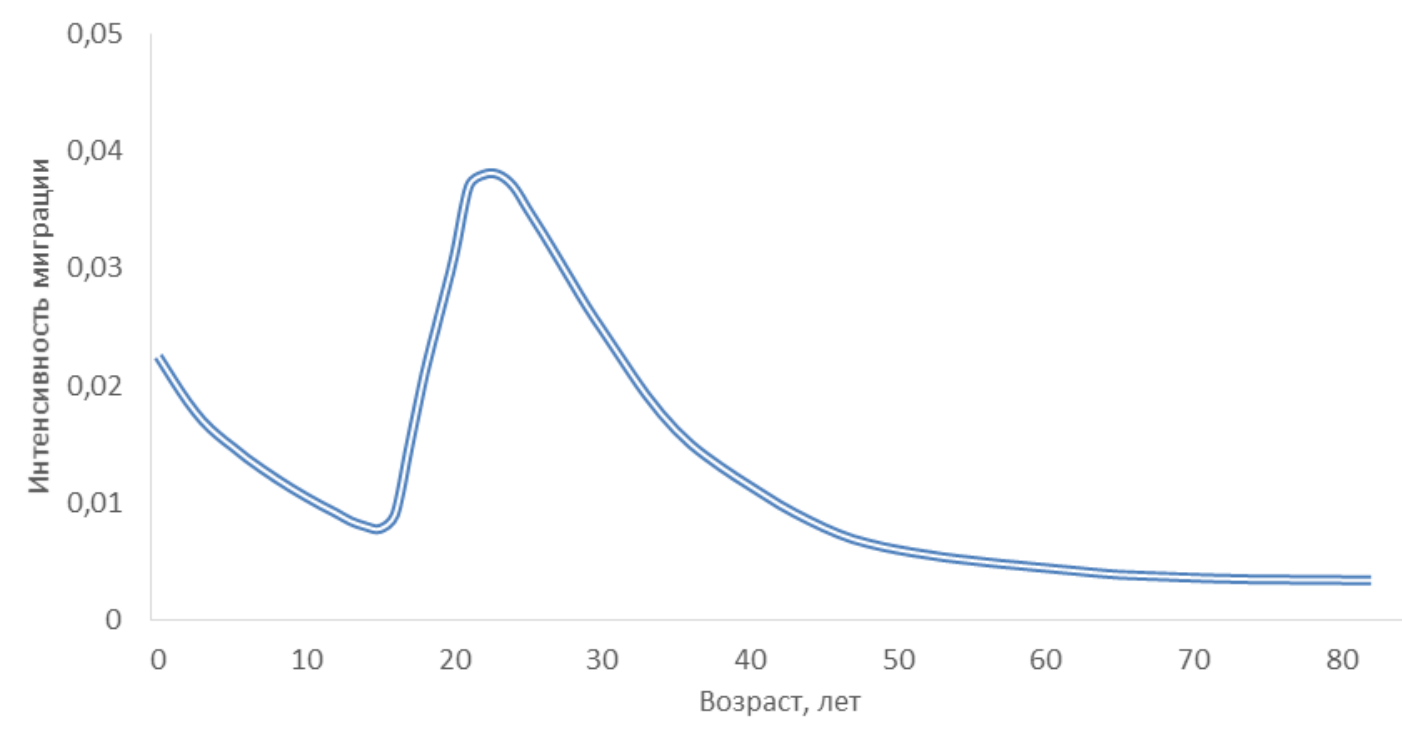

Рисунок 1. Стандартный возрастной профиль миграции

Источник: [Rogers, Castro 1981: 43].

Развивая работы по моделированию возрастных профилей миграции, Дж. Литтл и A. Роджерс [Little, Rogers 2007], используя функции Роджерса-Кастро, предложили типологию возрастных миграционных моделей для территорий, представляющих разные иерархические уровни: штаты, объединенные метрополитенские статистические ареалы, метрополитенские статистические ареалы (MCA), неметрополитенские округа. Было показано, что на территориях с численностью населения свыше 30 тыс. человек возможно с достаточной точностью анализировать и прогнозировать возрастные профили миграции, на меньших по численности населения территориях и на территориях с не совсем типичным возрастным составом населения (например, округах с военными базами или высокой долей престарелого населения) стандартная модель применима хуже. В результате кластеризации MCA были получены три класса: «стандартный» (193 MCA), «с доминантой ранней карьеры» (41 МСА) и «с доминантой старших возрастов» (20 MCA).

Стандартный возрастной профиль миграции неоднократно тестировался в разных странах, на миграционных потоках разной направленности и с проверкой дополнительных гипотез. Например, П. Смит, Дж. Раймер и К. Корадо [Smith, Raymer, Corrado 2010] изучали возрастные профили мигрантов применительно к миграции между графствами Англии в зависимости от их принадлежности разным социально-экономическим группам и пришли к заключению, что пенсионерам, студентам, занятым по найму, владельцам бизнеса, безработным, экономически неактивным свойственны неодинаковые возрастные графики миграции. С. Калогироу [Kalogirou 2005] показала, что разные возрастные особенности свойственны мигрантам, перемещающимся на короткие и длинные расстояния. В целом миграционные стратегии для 16-29-летних стали более разнообразными, а для населения 60 лет и старше - менее вариативными, чем несколько десятилетий назад. К. Гейст и П. Мак- 
Манус [Geist, McManus 2008] продемонстрировали, что пространственная мобильность в первую очередь является ответом на потребности, порожденные не составом семьи как таковым, а изменениями в ее составе, появление детей усиливает мобильность. Н. Байдл и C. Проут [Biddle, Prout 2009] выявили различия в кривых возрастной мобильности для коренного и некоренного населения Австралии. В работе Дж. Миллигтона [Millington 2000] показано, как реагирует возрастной профиль миграции на различные миграционные стимулы (жилье, климат, инфляцию и др.). Т. Вилсон [Wilson 2010], считая, что стандартный возрастной профиль имеет слабые объяснительные возможности по отношению к пикам в интенсивности миграции в молодых возрастах, предложил расширение стандартной модели путем добавления кривой студентов для регионов, которые принимают значительную студенческую миграцию. Ряд работ, анализирующих возрастные особенности миграции на нижнем пространственно-иерархическом (поселенческом) уровне, связывают возрастные профили миграции с типом и пространственным положением населенных пунктов: например, центральные города мегалополисов притягивают молодое население и имеют соответствующие профили миграции, а пригороды и средние города популярны у населения средних возрастов [Plane, Jurjevich 2009; Amcoff, Westholm 2007; Fuguitt, Heaton 1995]. Таким образом, связи между возрастными особенностями миграционных потоков и территориями выхода и вселения, а также специфика территорий по этим особенностям в зарубежной литературе изучаются давно и многогранно.

\section{МЕТОДИКА И ДАННЫЕ}

Для анализа региональной картины возрастных профилей прибывших и выбывших в России использовались данные о внутренней межрегиональной миграции по всем регионам России в разрезе однолетних возрастных групп за 2011-2015 гг. Выбор временного интервала продиктован тем, что в российской статистике миграции в 2011 г. произошли серьезные изменения: начали разрабатываться данные не только о мигрантах, зарегистрированных по месту жительства, но и о зарегистрированных по месту пребывания на срок 9 месяцев и более [Население России... 2014]. В результате число учтенных миграций в пределах страны увеличилось с 1,9 млн человек в 2010 г. до более чем 4 млн в 2015 г., число миграций между регионами - с 875 тыс. до 2083 тыс. соответственно. В разработку, в частности, были включены учебные мигранты, ранее учитываемые плохо [Чудиновских 2005], что повысило показатели интенсивности миграции молодежи. Однако интенсивность миграции увеличилась во всех возрастных группах.

Для расчетов возрастных коэффициентов интенсивности миграции были использованы также данные о возрастном составе населения регионов России за указанные годы в разрезе 1-летних возрастных групп по 83 регионам России ${ }^{1}$.

Применялся метод кластеризации (по показателю доли прибывших/выбывших в отдельных возрастных группах к общему числу мигрантов) регионов методом k-средних с

\footnotetext{
${ }^{1}$ Без Крыма, соответствующие данные о котором за 2011-2014 гг. отсутствуют.
} 
использованием программы SPSS. Устойчивость кластеров в данном исследовании не оценивалась, число кластеров было определено экспертным путем. Метод кластеризации применялся исключительно для группировки регионов и последующего анализа межгрупповых различий типичных распределений прибывших и выбывших по возрасту.

Базовый показатель для выделения групп рассчитывали следующим образом: 1) суммировали числа прибывших/выбывших в каждом возрастном интервале по всем регионам данной группы; 2) полученные значения для возрастных интервалов соотносили с суммарным числом прибывших/выбывших мигрантов (в промилле).

\section{ОСНОВНЫЕ РЕЗУЛЬТАТЫ И ИХ ОБСУЖДЕНИЕ}

Межрегиональная миграция имеет структурные особенности, выраженные в преобладании в потоке населения в молодых возрастах. Ситуация в России в этом не уникальна, в других странах также в миграции чаще участвует молодежь, и возрастной профиль, представленный на рисунке 2, в общем контуре схож с представленным выше модельным (рисунок 1). Выраженный пик в возрасте 18 лет объясняется миграцией, связанной с получением образования, после этого интенсивность миграции снижается. На возраста 1629 лет приходится почти $40 \%$ всех учитываемых статистикой межрегиональных миграционных перемещений в России. Самой низкой интенсивностью миграции в России характеризуются пожилые люди и дети школьных возрастов.

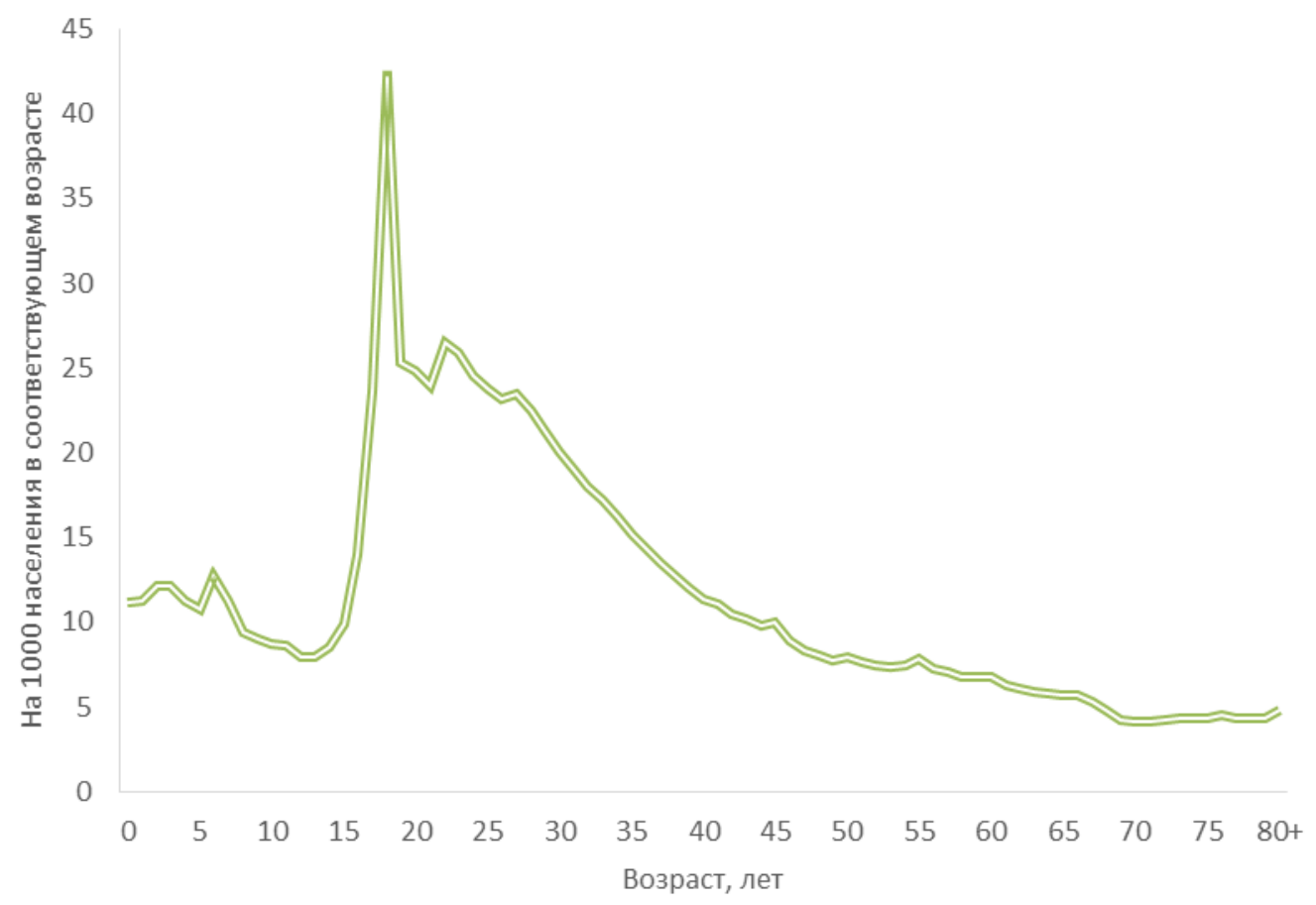

Рисунок 2. Распределение межрегиональных мигрантов по возрасту, Россия, 20112015 гг., в среднем за год

Источник: Расчеты авторов на основе данных Росстата. 


\section{Региональная специфика возрастного распределения показателей прибывиих и выбывщих}

Возрастной состав мигрантов по отдельным регионам России отличается от общероссийского профиля. Для первичного анализа были рассчитаны показатели интенсивности прибытий и выбытий в межрегиональной миграции за 2011-2015 гг. для каждого региона России. Однако сопоставление регионов по характеру кривых прибытий/выбытий затрудняют различия в общей интенсивности миграции между регионами: при средней по стране интенсивности прибытий 12 промилле за год в ряде регионов Северного Кавказа она составляет 5-6 промилле, тогда как в Московской области - 28, в Ленинградской области - 30, а в Чукотском АО - 63 промилле. Интенсивность выбытий варьируется от 6 промилле в Тюменской области до 70 промилле в Чукотском АО. В данной работе мы пытаемся выявить наиболее распространенные распределения прибывших и выбывших в/из регионов России и обозначить причины различий между регионами и их группами. Нас интересует не интенсивность миграции в той или иной возрастной группе, а соотношение отдельных возрастов в потоке, которые определяют профиль миграции.

Поэтому для сравнения использовали показатель доли прибывших/выбывших в отдельных возрастных группах к общему числу мигрантов. Данный показатель зависим от возрастной структуры населения региона выхода мигрантов, но он наиболее удобен для межрегиональных сравнений, так как нивелирует различия в общей интенсивности миграции между отдельными регионами.

Регионы России были разбиты на группы, выделенные по особенностям возрастного распределения прибывших и выбывших в среднем за 2011-2015 гг. Результаты, показывающие средние значения по группам, рассчитанные описанным выше образом, представлены на рисунках 3 и 5. Эти рисунки иллюстрируют основные различия между выделенными группами. На рисунках 4 и 6 показаны отличия распределений прибывших от средних по России значений.

Группы регионов, выделенные по распределению прибывиих межрегиональных мигрантов по возрасту, неравноценны по числу формирующих их регионов. К первой группе - без сильного пика в возрасте 18 лет, связанного прежде всего с участием в учебной миграции (помимо учебной миграции, в этом возрасте люди могут переселяться с иными целями, но учебный мотив явно доминирует; так, в 2015 г. среди всех межрегиональных мигрантов в возрастах 18-19 лет, указавших причину миграции, 76\% назвали причину «в связи с учебой»), но с довольно выраженным пиком в возрасте 20-30 лет, - относятся 19 регионов. Здесь в основном находятся регионы севера и востока страны (Мурманская область, ХМАО, Приморский край и др.), а также республики Северного Кавказа. В этих регионах недостаточно развита система учреждений высшего профессионального образования, учебный мотив миграции практически не имеет смысла, поэтому основной приток мигрантов осуществляется в несколько более старших возрастах, уже после времени получения образования. Как показывают исследования [Кашницкий, Мкртчян, Лешуков 2016], регионы, входящие в данную группу, характеризуются оттоком молодых мигрантов в другие регионы. 
Близкое к этому распределение мигрантов (отсутствие яркого «пика» в наиболее молодых возрастах) характерно для регионов второй группы (13 субъектов РФ), к которой принадлежат несколько субъектов Севера, но кроме них - Московская и Ленинградская области, Краснодарский край, Республика Адыгея, а также несколько других, некомпактно расположенных областей Европейской части. В данной группе пик миграции смещен к старшим возрастам, активный приток населения (больший, чем в других группах) наблюдается в возрасте 30-60 лет. Этому может быть два объяснения: возвратная миграция и профессиональная деятельность. Предположение о доминировании возвратной миграции в регионы данной группы, на наш взгляд, не вполне логично, так как группа объединяет субъекты РФ, не испытывающие сильного оттока на учебу (например, Московская, Ленинградская области, Краснодарский край), соответственно в них некому возвращаться. Поэтому предполагаем, что приток в регионы данной группы в большей мере связан с профессиональной самореализацией, с карьерным ростом и др. В частном случае Московской и Ленинградской областей наиболее важно, что они входят в состав крупнейших городских агломераций и сюда вселяются люди, ориентированные на рынок труда их центральных городов.

Регионы, формирующие третью группу, по возрастному распределению входящего потока мигрантов наиболее близки к общестрановому профилю; их 29. Одной из характеристик регионов данной группы является то, что здесь в числе прибывших повышена доля детей, как следствие высокой доли людей в возрастах их потенциальных родителей (25-50 лет).

К данной группе относится большинство регионов Центральной России (включая Москву), Приволжья и Юга Сибири. Здесь также находятся Республики Чечня и Ингушетия, но возрастное распределение прибывших в них, кроме выраженного пика в 1819 лет, схоже с регионами второй группы. Причины отличий возрастных распределения прибытий в эти два региона от других республик Северного Кавказа не вполне понятны. Вероятно, они связаны в том числе с качеством статистического учета населения. Косвенным основанием для высказывания таких опасений является существование в Республике Ингушетии на протяжении всего периода после переписи населения 2010 г. миграционного прироста населения, этим республика отличается от всех соседних регионов. В целом проблемы с качеством учета населения в республиках Северного Кавказа неоднократно описывались [Андреев 2012; Мкртчян 2011]. Также, даже на фоне сравнительно «старого» возрастного профиля миграции в регионы данной группы, выделяются прибытия в Белгородскую область: сюда переселяется немало лиц в возрасте 50-65 лет, что сближает данный регион также с регионами второй группы. По-видимому, Белгородская область в силу благоприятных природно-климатических условий и социально ориентированной модели регионального развития привлекательна прежде всего для лиц предпенсионных и пенсионных возрастов. Играет роль и приграничное положение с Украиной, в случае возвратной миграции с «северов» это оказывается немаловажным: например, проще посещать оставшихся на Украине родственников, при этом не переселяясь из России [Замятина 2014].

В четвертую группу вошли 22 региона с более выраженным пиком миграции в возрасте поступления в вуз, чем в целом по стране, и одновременно менее активным 
участием в миграции представителей возрастов старше 30 лет. К ним относятся регионы разных частей страны (за исключением Севера и Северного Кавказа), такие как Ярославская, Рязанская, Иркутская, Свердловская области, Красноярский край. Также к этой группе принадлежит Санкт-Петербург - крупнейший в России (наряду с Москвой) центр притока учебных мигрантов. Наиболее близка к этой группе регионов стоящая особняком Томская область. Это территория с гипертрофированно выраженным молодежным профилем прибывших. $61 \%$ прибывших в Томскую область - люди в возрасте 16-29 лет, в том числе 12\% прибывших приходится на возраст 18 лет. Томские вузы, без преувеличения, «дирижируют» всей миграцией в области, старшие возрастные группы населения представлены в потоке существенно более скромно, чем в других регионах страны.

Еще одним регионом-исключением является Республика Тыва. Возрастной состав прибывших в нее также характеризуется выраженным молодежным профилем, но не таким острым, как в Томской области. Конечно, Тува не является центром притока учебных мигрантов. В данном случае мы имеем дело с последствиями трансформации методики текущего учета миграции 2011 г., в результате которой изменения затронули не только прибытия, но и выбытия: ранее выбывшие из республики в другие регионы мигранты по мере окончания у них срочной регистрации считаются «прибывшими» в регион. Косвенно об этом свидетельствует «растянутость» пика прибытий: в отличие от других регионов он продолжается до возраста 25 лет. Иными словами, случай Тувы - это, возможно, в некоторой мере отражение «фиктивного» обратного потока мигрантов.

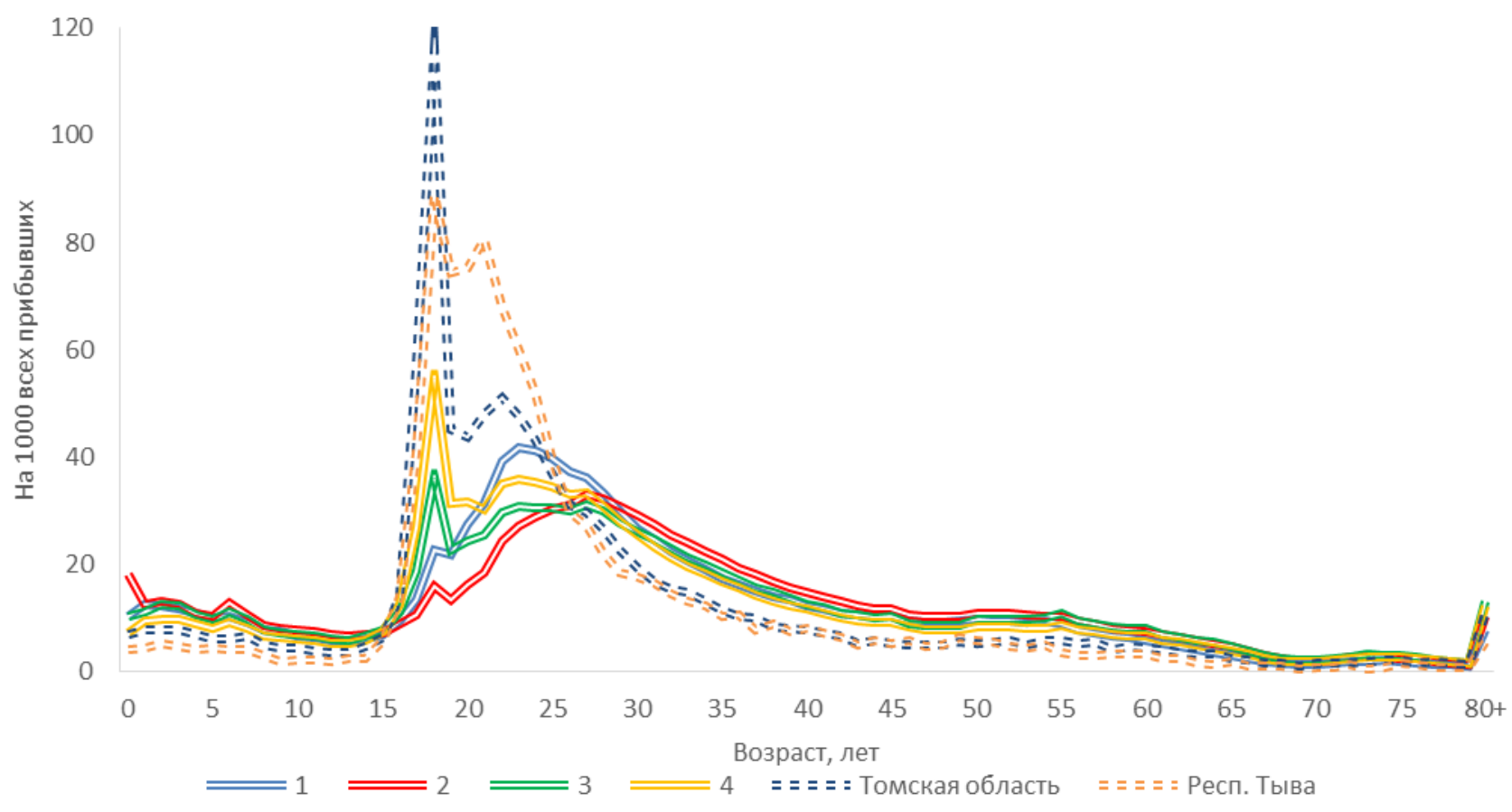

Рисунок 3. Прибывшие по однолетним возрастным группам в суммарном числе прибывших в регион, четыре группы регионов, в среднем за 2011-2015 гг., на 1000

Источник: Расчеты авторов на основе данных Росстата.

Примечания: Республика Тыва и Томская область не принадлежат ни к одной из групп. 


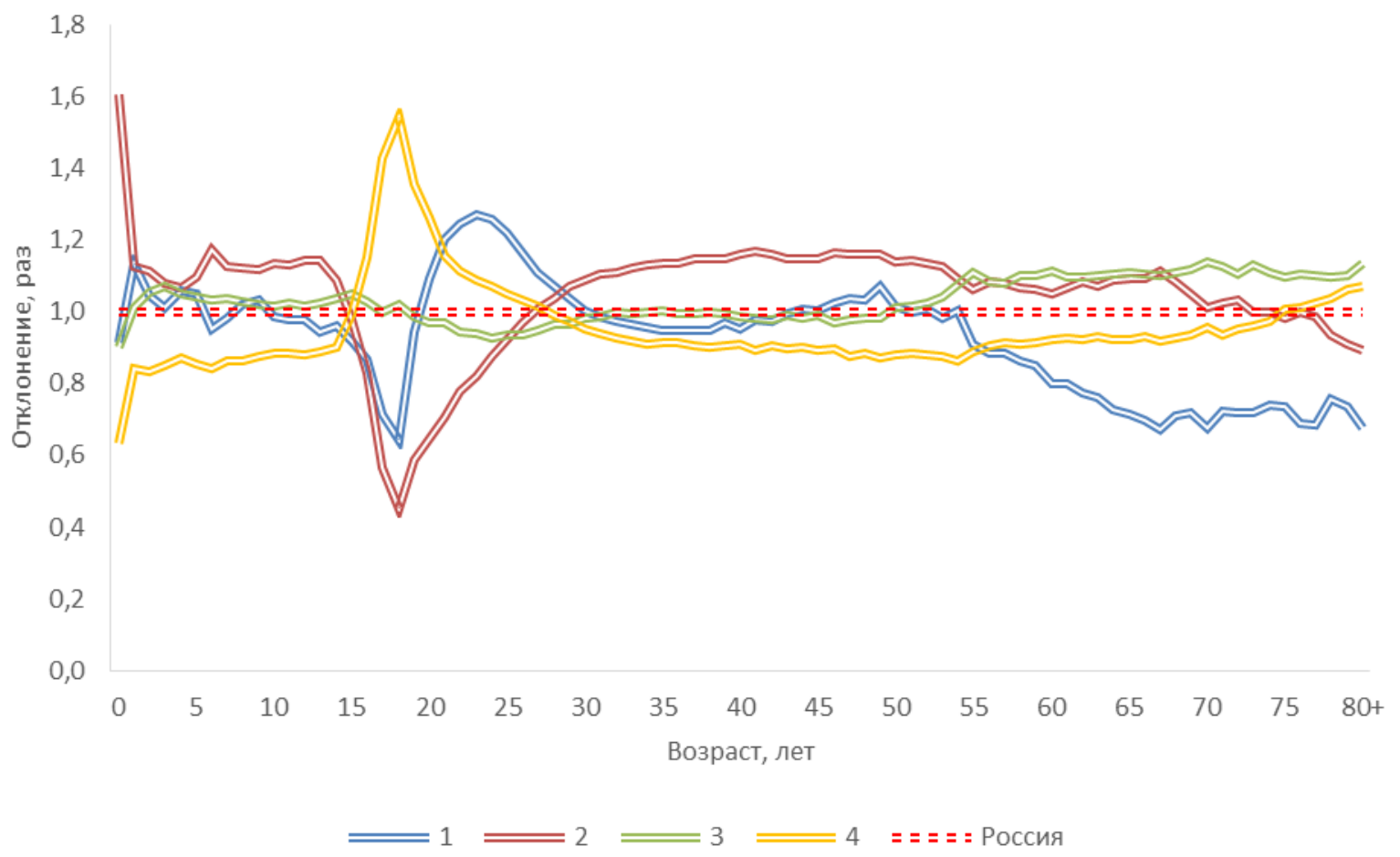

\section{Рисунок 4. Отклонение долей прибывших в соответствующих возрастах от средних значений по России по четырем группам регионов}

Источник: Расчеты авторов на основе данных Росстата.

Примечание: По оси абсиисс - возраст, лет, по оси ординат - отклонение, раз.

По распределению выбывших межрегиональных мигрантов регионы были разделены на четыре группы. Первая группа, состоящая из 49 субъектов РФ (т.е. почти две трети всех регионов), объединяет регионы, расположенные во всех частях страны, за исключением, пожалуй, зоны Севера. Профиль выбытий здесь очень похож на общероссийский: выраженный, но не большой пик в возрасте начала обучения в вузе, спад доли прибывших в возрасте 19-20 лет и второй, более продолжительный пик в возрасте 2130 лет. Очевидно, что типичная для России ситуация - выезд части молодежи для обучения в другом регионе и последующий, более растянутый во времени, отток в возрасте после получения образования (второй, сглаженный пик) до возраста создания семьи и обзаведения детьми. После этого доля участвующих в миграции снижается.

Однако в данной группе есть регионы, немного отличающиеся по возрастному распределению выбывших. Например, Красноярский край, имеющий небольшой третий пик выбытий в возрасте 50-60 лет. Этот внутренне очень неоднородный регион включает в свой состав южную территорию, мало отличающуюся по условиям жизни от соседних регионов юга Сибири (к ней принадлежит и г. Красноярск с крупным по российским меркам университетом и целым рядом других вузов), а также отнесенный к зоне Крайнего Севера двухсоттысячный Норильск и другие территории Крайнего Севера. Юг Красноярского края «отвечает» за выбытия в молодых возрастах, а север - в ранних пенсионных (что сближает профиль миграции с четвертой группой регионов, в основном северных), но доля севера в 
населении края не так высока, чтобы кардинальным образом поменять общий возрастной профиль миграции.

Вторая группа представлена всего двумя, но очень значимыми на миграционном поле страны субъектами - г. Москвой и Московской областью. Здесь в потоке выезжающих практически нет молодежного пика, основной выезд осуществляется в широком промежутке возрастов от 20 до 40 лет. С одной стороны, это могут быть мигранты, «не прижившиеся» в столичном регионе, в том числе возвращающиеся после завершения профессионального образования в свои регионы (включая «фиктивные» выбытия - по мере прекращения срочной регистрации, например, на период обучения). С другой стороны, и на это косвенно указывает высокая доля детей в возрасте 0 лет среди выезжающих из Москвы, поток могут формировать семьи, переезжающие в другие регионы, в первую очередь в Московскую область, приурочившие рождение детей к изменению жилищных условий (например, покупке квартиры или дома в Московской области). Подобные процессы имеют большое распространение в западных странах [Plane, Heins 2003; Geist, McManus 2008; Swiaczny, Graze, Schloemer 2008; Plane, Jurjevich 2009] и начинают просматриваться в Московском столичном регионе [Мкртчян 2015; Махрова, Нефедова, Трейвиш 2012]. Одновременно из Московской области есть встречный поток.

Третья группа регионов не имеет четкой территориальной локализации, ее отличает более выраженный, чем по стране в целом, пик выезда в возрасте 18 лет и в «поствузовское» время, равно как и более сильный спад доли выбытий в более старших возрастах. К этой группе регионов относятся, например, Республики Башкортостан и Татарстан, Томская, Липецкая области, Республика Дагестан. Выбытия здесь связаны как с желанием молодежи учиться и работать в других регионах, так и с выездом после окончания учебы в другие регионы страны ранее прибывших мигрантов (самый яркий пример - Томская область, рынок труда которой не может абсорбировать большую часть выпускников вузов, они возвращаются в свои регионы или в регионы, где есть рабочие места, соответствующие полученному профилю образования [Замятина 2012]).

Республика Тыва по возрастному профилю выбытий снова не похожа на другие регионы России, ее отличает острый пик выбытий в возрастах 18-25 лет и последующий резкий спад оттока. Близки к ней по виду профиля Республики Ингушетия и Алтай, здесь среди выбывающих также очень высока доля молодежи.

Четвертая группа объединяет северные регионы страны - от Мурманской области на западе до Сахалинской области и Чукотского АО на востоке. Важнейшая отличительная особенность распределения выбывших из этих регионов (рисунки 5, 6) - наличие третьего пика выбытий в возрастах от 50 до 65 лет, не уступающего по мощности пикам в молодых возрастах. Население российского Севера, сформированное в основном мигрантами в первом поколении, по наступлении пенсионного возраста (а в этих регионах срок выхода на пенсию у многих на 5-10 лет раньше, чем в целом по стране) активно выезжает в другие регионы страны, в том числе на территории с более благоприятными природноклиматическими условиями, возвращается в места своего проживания до переезда на север [Замятина 2014]. Такого значимого пика выезда в старших возрастах, кроме регионов Севера, больше нет нигде в России. 


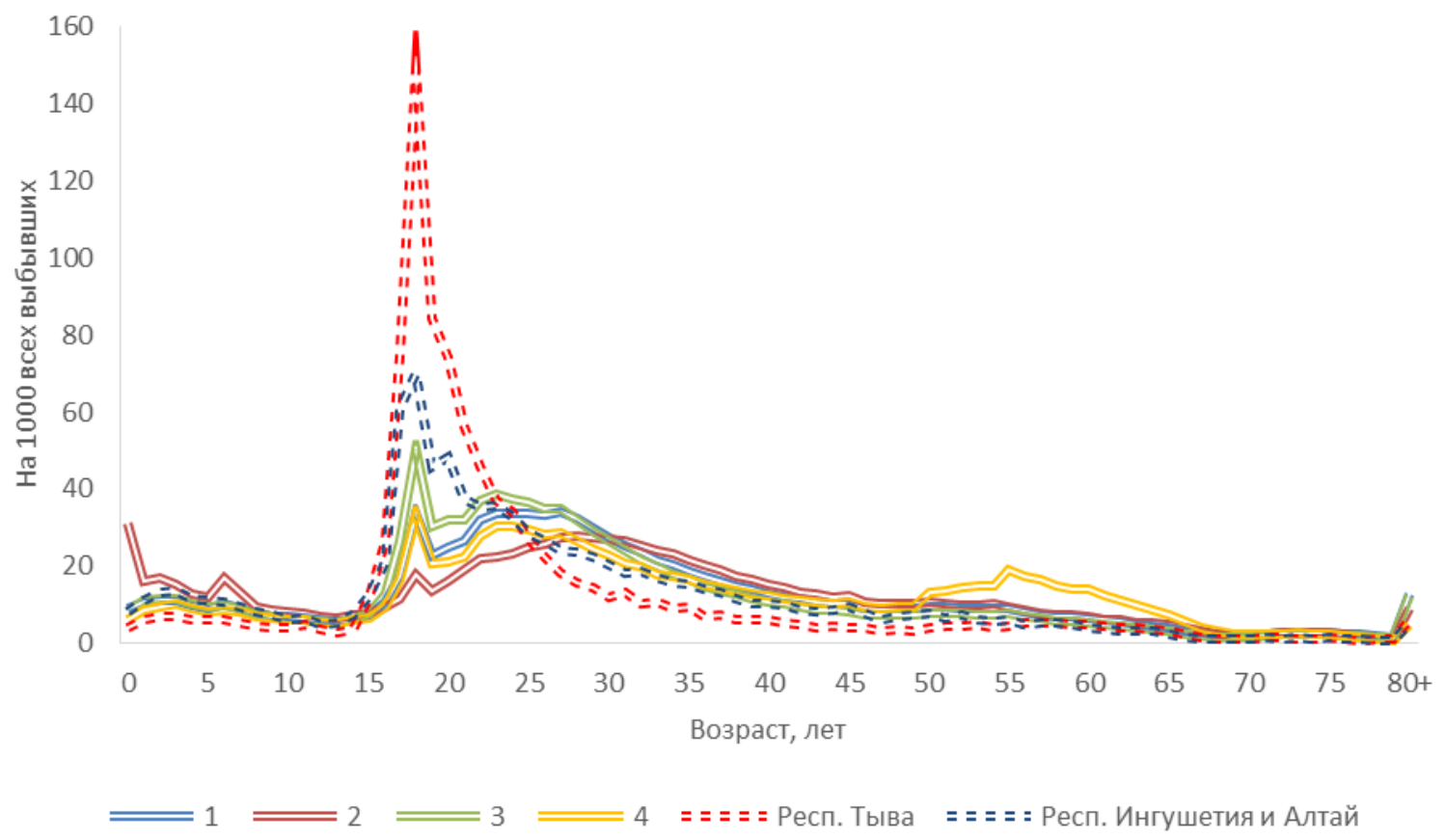

Рисунок 5. Выбывшие по однолетним возрастным группам в суммарном числе выбывших из региона, четыре группы регионов, в среднем за 2011-2015 гг., на 1000

Источник: Расчеты авторов на основе данных Росстата.

Примечания: Республики Тыва, Ингушетия и Алтай не принадлежат ни к одной из групп.

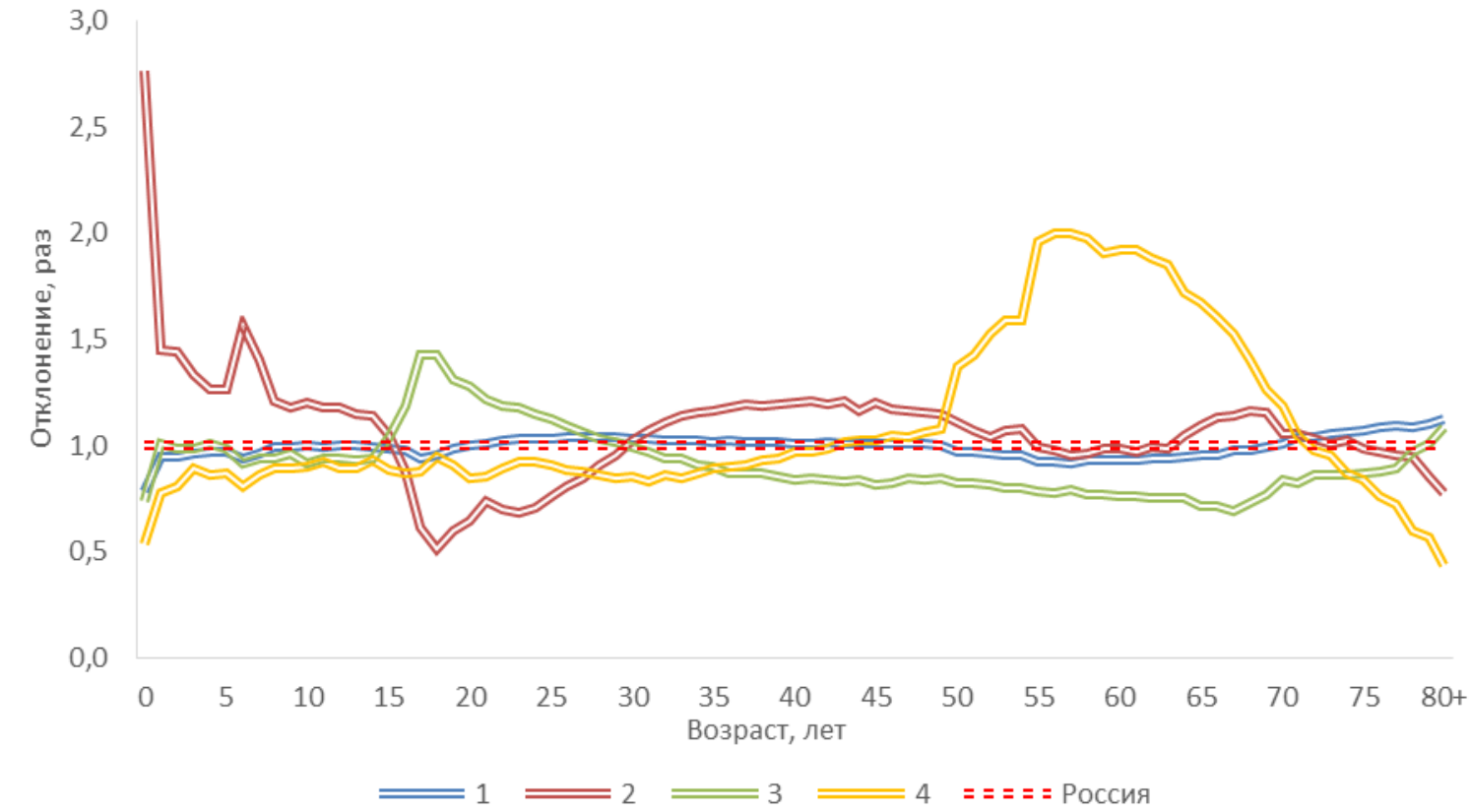

Рисунок 6. Отклонение долей выбывших в соответствующих возрастах от средних значений по России по четырем группам регионов

Источник: Расчеты авторов на основе данных Росстата.

Примечание: По оси абсиисс - Возраст, лет, по оси ординат - Отклонение, раз. 
Таким образом, возрастное распределение мигрантов, участвующих во внутренней межрегиональной миграции, имеет существенные различия по регионам. В отдельных регионах пики прибытий в молодых возрастах могут сопровождаться еще более выраженным пиком выбытий в том же возрасте или с небольшим лагом (как, например, в Томской области). Большая доля в потоке прибытий лиц молодых трудоспособных возрастов может сопутствовать их не менее активному оттоку как реальному (промывной режим миграции), так и фиктивному, связанному с окончанием срока временной регистрации, не всегда сопровождающемуся реальным возвращением в регион выхода. Приток в молодых возрастах может через много лет вести к активному выезду в старших трудоспособных и молодых пенсионных возрастах (так происходит в регионах российского Севера). Практически однонаправленный поток молодежи в Москву и Санкт-Петербург по мере взросления сменяется разнонаправленным движением: это может быть возврат к месту прежнего жительства или переезд в пристоличные области, на периферию крупнейших в стране агломераций и циркулярное движение в их пределах.

\section{ЗАКЛЮЧИТЕЛЬНЫЕ ЗАМЕЧАНИЯ}

В данной статье мы попытались описать региональные особенности возрастного распределения межрегиональных миграционных потоков. Но даже этот первый анализ позволяет сделать некоторые выводы, наметить пути перспективных исследований. В последние годы появляются работы, посвященные анализу миграции молодежи, но пока совершенно не изучены применительно к России вопросы пространственной мобильности иных возрастных групп населения. Этому есть свои объяснения. Действительно, по сравнению с молодежной миграцией, потоки, например, лиц пожилого возраста могут показаться незначимыми, но это так, только если смотреть на данные по стране в целом. В отдельных регионах этот вид миграции оказывается вполне сопоставимым по интенсивности с балансом иных возрастных групп. По отношению к выбытиям - это северные регионы страны; соответственно большей, чем в других субъектах, долей пожилых в прибытиях отличаются регионы Центра, Юга и Северо-Запада.

Демографическое и социально-экономическое влияние миграции населения разных возрастов на регионы заметно различается. В регионах с ярко выраженным молодежным притоком миграция ведет к омолаживанию населения и необходимости подстройки социальной инфраструктуры под нужды и потребности молодых. В других ускоренный выезд молодых мигрантов по отношению к переселенцам других возрастов, наоборот, способствует более быстрому постарению населения регионов. Ускоренный рост численности и доли старших возрастов в регионах может быть вызван также преферентным притоком в них пожилого населения. Наконец, встречаются регионы, в которых наблюдается комбинация усиленного притока мигрантов самых активных трудоспособных возрастов с оттоком пожилых.

Как мы и ожидали, анализ показал, что различия между регионами - даже расположенными относительно недалеко друг от друга - недооцениваются. Например, северная дислокация вовсе не однозначно маркирует регионы как притягивающие 
население преимущественно активных трудоспособных возрастов. Достаточно неожиданным, например, был «старый» профиль прибытий в Чукотский АО.

Проведенный нами анализ также показал, что многие регионы страны внутренне неоднородны (как в рассмотренном примере с Красноярским краем). На региональном уровне мы не можем видеть, насколько различен по возрастной составляющей баланс миграции региональных центров и внутрирегиональной периферии, отдельных (северных или южных, западных или восточных) частей регионов. Ощущаются только некоторые контуры этой неоднородности, прежде всего в тех регионах, где региональные центры составляют значительную долю в населении региона. Впрочем, рассмотрение этих вопросов - предмет самостоятельного исследования.

\section{ЛИТЕРАТУРА}

Андреев Е.М. (2012). О точности результатов российских переписей населения и степени доверия к разным источникам информации // Вопросы статистики. 11: 21-35.

Варшавская Е.Я., О.С. Чудиновских (2014). Миграционные планы выпускников региональных вузов России // Вестник Московского университета. Сер. 6: Экономика. 3: $36-58$.

Гридасов Г.Н., Н.О. Захарова, Е.С. Балуева (2011). Сравнительный анализ динамики миграционного прироста пожилого населения Самарской области // Успехи геронтологии. 24. 4: 707-712.

Дементьева С.В., Е.В. Гиниятова (2012). Учебная миграция в Томский политехнический университет: механизм и практики эффективной адаптации // Известия Томского политехнического университета. Инжиниринг георесурсов. 321. 6: 187-190.

Доклад о развитии человека 2009 (2009). Преодоление барьеров: человеческая мобильность и развитие. ПРООН.

Ермаков С.П., С.Ю. Никитина (2015). Возрастные особенности миграции населения в субъектах Российской Федерации в 2000-2010 гг. // Народонаселение. 3: 15-29.

Замятина Н.Ю. (2012). Метод изучения миграций молодежи по данным социальных интернет-сетей: Томский государственный университет как центр производства и распределения человеческого капитала (по данным социальной интернет-сети ВКонтакте) // Региональные исследования. 2: 15-29.

Замятина Н.Ю. (2014). Социальная лесотундра: географическая подвижность как элемент семейных траекторий жителей северных городов (на примере Норильска и Дудинки) // Неприкосновенный запас. 5 (97): 189-208.

Захаров С.В., Е.И. Иванова (1996). Региональная дифференциация рождаемости в России: 1959 - 1994 // Проблемы прогнозирования. 4: 109-130.

Катровский А.П. (1999). Учебная миграция в вузы России: факторы и мотивация // Миграция и урбанизация в СНГ и Балтии в 90-е годы / Под ред. Ж.А. Зайончковской. М.: Совет по миграциям стран СНГ, Центр демографии и экологии человека: 269-276.

Кашницкий И.С., Н.В. Мкртчян, О.В. Лешуков (2016). Межрегиональная миграция молодежи в России: комплексный анализ демографической статистики // Вопросы образования. 3: 169-203. 
Махрова А., Т. Нефедова, А. Трейвиш (2012). Москва: мегаполис? агломерация? мегалополис? // Демоскоп Weekly. 517-518. URL: http://demoscope.ru/weekly/2012/0517/demoscope517.pdf (дата обращения 02.10.2016).

Мкртчян Н.В. (2013). Миграция молодежи в региональные центры России в конце XX начале XXI века // Известия РАН. Сер. География. 6: 19-32.

Мкртчян Н.В. (2014). О влиянии миграции на возрастной состав населения регионов, городов и районов России // Научные труды ИНП РАН. М.: МАКС Пресс: 381-396.

Мкртчян Н.В. (2015). Миграция в Москве и Московской области: региональные и структурные особенности // Региональные исследования. 3: 107-116.

Мкртчян Н.В. (2011). Динамика населения регионов России и роль миграции: критическая оценка на основе переписей 2002 и 2010 гг. // Известия РАН. Сер. География. 5: 28-42.

Моисеенко В.М., О.С. Чудиновских (2000). Миграционные потоки пожилого населения в России // Психология зрелости и старения. 1: 28-35.

Население России 2001 (2002). Девятый ежегодный демографический доклад / Отв. Ред. А.Г. Вишневский. М.: КД «Университет»: 47-50.

Население России 2012 (2014). Двадцатый ежегодный демографический доклад / Отв. ред. А.Г. Вишневский. М.: Изд. дом Высшей школы экономики: 309-317.

Рахманова Г. (1994). Возрастные профили миграции в России и ее регионах: 80-е и начало 90-х гг. // Миграционные процессы после распада СССР. Программа по исследованию миграции. Вып. V / Науч.ред. Ж.А. Зайончковская. М.: 82- 113.

Тарасова Е.В. (2013). Особенности миграции населения старше трудоспособного возраста в Алтайском крае // Социальная интеграция и развитие этнокультур в Евразийском пространстве. 1: 150-153.

Флоринская Ю.Ф., Т.Г. Рощина (2008). Оценка уровня миграционной мобильности молодежи малых российских городов (по опросам выпускников школ) // Проблемы прогнозирования. 3: 125-139.

Чихичин В.В. (2014). Учебная миграция на Северном Кавказе: причины, география и возможные проблемы // Наука. Инновации. Технологии. 2: 161-178.

Чудиновских О.С. (2005). Учет миграции в России: причины и последствия кризиса // Демоскоп Weekly. 185-186. URL: http://demoscope.ru/weekly/2005/0185/analit03.php (дата обращения 01.10.2016).

Чудиновских О.С., М.Б. Денисенко (2003). Где хотят жить выпускники российских вузов? // Демоскоп Weekly. 119-120. URL: http://demoscope.ru/weekly/2003/0119/tema01.php (дата обращения 01.10.2016).

Эмбрехт Р.В. (2011). Роль образовательной миграции в демографическом развитии Томской области (2000-2009 гг.) // Вестник Томского государственного университета. 348: 76-79.

Amcoff J., E. Westholm (2007). Understanding rural change - demography as a key to the future // Futures. 39 (4): 363-379.

Biddle N., S. Prout (2009). The geography and demography of Indigenous temporary mobility: an analysis of the 2006 census snapshot // Journal of population research. 26: 305-326. DOI 10.1007/s12546-010-9026-1. 
Fuguitt G., T. Heaton (1995). The impact of migration on the nonmetropolitan population age structure, 1960-1990. // Population research and policy review. 14: 215-232.

Geist C., P. McManus (2008). Geographical mobility over the life course: motivations and implications //Population, space and place. 14: 283-303. DOI: 10.1002/psp.508.

Kalogirou S. (2005). Examining and presenting trends of internal migration flows within England and Wales //Population, space and place. 11: 283-297. DOI: 10.1002/psp.376.

Kashnitsky I. S., N.V. Mkrtchyan (2014). Russian periphery is dying in movement: a cohort assessment of Russian internal youth migration based on census data. NIDI working papers. 14.

Little J., A. Rogers (2007). What can the age composition of a population tell us about the age composition of its out-migrants? // Population, space and place. 13: 23-29. DOI: 10.1002/psp.440.

Millington J. (2000). Migration and age: the effect of age on sensitivity to migration stimuli // Regional studies. 34 (6): 521-533.

Pittenger D.B. (1974). A typology of age-specific net migration rate distributions // Journal of the American institute of planners. 40 (4): 278-283, DOI: 10.1080/01944367408977480.

Plane D., F. Heins (2003). Age articulation of U.S. inter-metropolitan migration flows // The annals of regional science. 37: 107-130.

Plane D., J. Jurjevich (2009). Ties that no longer bind? The patterns and repercussions of agearticulated migration // The professional geographer. 61(1): 4-20. DOI: $10.1080 / 00330120802577558$.

Rogers A., L. Castro (1981). Model migration schedules // Research report RR-81-30, IIASA, Laxenburg, Austria.

Rogers A., L. Castro (1986). Migration // Migration and settlement. A multiregional comparative study / Rogers A. and F. Willekens, eds. Dordrecht: Reidel Publ.: 157-208.

Smith P. W. F., J. Raymer, G. Corrado (2010). Combining available migration data in England to study economic activity flows over time // Journal of the royal statistical society. 173 (4): $733-753$.

Swiaczny F., Ph. Graze, C. Schloemer (2008). Spatial Impacts of demographic change in Germany - urban population processes reconsidered // Zeitschrift für Bevőlkerungswissenschaft. 33 (2):181—206.

Wilson T. (2010). Model migration schedules incorporating student migration peaks // Demographic research. 23: 191-222. 


\title{
INTERREGIONAL MIGRATION IN RUSSIA: AGE CHARACTERISTICS
}

\author{
LILIYA KARACHURINA, NIKITA MKRTCHYAN
}

The paper analyses the age structure of internal migration across Russian regions. We use data on the age of interregional migrants in the regions of Russia in 2011-2015 given for one-year age groups and data on the population size of the Russian regions by one-year age groups.

The regions were grouped into clusters (by the ratio of arrivals/departures per age group to the total number of migrants) using the method of k-means clustering with SPSS. The results of the analysis indicate that, as in other countries, the peak of migration is observed at young ages, which is explained by mass enrollment of school graduates in institutions of higher education. As people become older, their migration activity declines. In some cases, regions experience another migration peak in young old age groups: after retirement, people may move to a place more appropriate for 50-60-year-olds or return to their previous place of residence.

The analysis also revealed significant variations in age patterns of interregional migration, both for inflows (arrivals) and outflows (departures). These differences mainly concern the level of the migration peak at young ages and the presence of additional migration peaks at other ages.

Key words: age, migration, inter-regional migration, the age profile, regions of Russia.

LILIYA KARACHURINA (lkarachurina@hse.ru), NATIONAL RESEARCH UNIVERSITY HighER SCHOOL OF ECONOMICS, RUSSIA.

Nikita Mkrtchyan, National Research University Higher School of Economics, Russia.

THE RESUlTS OF THE PROJECT "DEMOGRAPHIC DEVELOPMENT IN RUSSIA IN 2005-2015 IN THE CONTEXT OF LONG-TERM TRENDS", CARRIED OUT WITHIN THE FRAMEWORK OF THE BASIC RESEARCH PROGRAM AT THE NATIONAL RESEARCH UNIVERSITY HIGHER SCHOOL OF ECONOMICS (HSE) IN 2016, ARE PRESENTED IN THIS PAPER.

DATE RECEIVED: SEPTEMBER 2016.

\section{REFERENCES}

Amcoff J., E. Westholm (2007). Understanding rural change - demography as a key to the future // Futures. 39 (4): 363-379.

Andreev E.M. (2012). O tochnosti rezul'tatov rossiyskikh perepisey naseleniya i stepeni doveriya $\mathrm{k}$ raznym istochnikam informatsii [On accuracy of Russia population censuses results and level of confidence in different sources of information] // Voprosy statistiki [Problems in statistics]. 11:21-35.

Biddle N., S. Prout (2009). The geography and demography of Indigenous temporary mobility: an analysis of the 2006 census snapshot // Journal of population research. 26: 305-326. DOI $10.1007 / \mathrm{s} 12546-010-9026-1$.

Chihichin V.V. (2014). Uchebnaya migratsiya na Severnom Kavkaze: prichiny, geografiya i vozmozhnye problem [Study migration in the North Caucasus: the causes, geography and potential problems] // Nauka. Innovatsii. Tekhnologii [Science. Innovation. Technologies]. 2: $161-178$.

Chudinovskih O.S. (2005). Uchet migratsii v Rossii: prichiny i posledstviya krizisa [The accounting of migration in Russia: reasons and consequences of the crisis] // Demoscope 
Weekly. 185-186. URL: http://demoscope.ru/weekly/2005/0185/analit03.php (accessed 01.10.2016).

Chudinovskih O.S., M.B. Denisenko (2003). Gde khotyat zhit' vypuskniki rossiyskikh vuzov? [Where graduates of the Russian higher education institutions want to live?] // Demoscope Weekly. 119-120. URL: http://demoscope.ru/weekly/2003/0119/tema01.php (accessed 01.10.2016).

Dement'eva S.V., E.V. Ginijatova (2012). Uchebnaya migratsiya v Tomskiy politekhnicheskiy universitet: mekhanizm i praktiki effektivnoy adaptatsii [Study migration in Tomsk polytechnic university: the mechanism and practice of effective adaptation] // Izvestiya Tomskogo politekhnicheskogo universiteta. Inzhiniring georesursov [Bulletin of the Tomsk polytechnic university. Engineering georesources]. 321. 6: 187-190.

Ermakov S.P., S.Ju. Nikitina (2015). Vozrastnye osobennosti migratsii naseleniya v sub"ektakh Rossiyskoy Federatsii v 2000-2010 gg. [Age characteristics of migration in the Russian Federation in 2000-2010 years] // Narodonaselenie [Population]. 3: 15-29.

Florinskaja Ju.F., T.G. Roshhina (2008). Otsenka urovnya migratsionnoy mobil'nosti molodezhi malykh rossiyskikh gorodov (po oprosam vypusknikov shkol) [Evaluation of migration youth mobility of small Russian cities (surveys of school leavers)] // Problemy prognozirovaniya [Studies on Russian economic development]. 3: 125-139.

Fuguitt G., T. Heaton (1995). The impact of migration on the nonmetropolitan population age structure, 1960-1990. // Population research and policy review. 14: 215-232.

Geist C., P. McManus (2008). Geographical mobility over the life course: motivations and implications //Population, space and place. 14: 283-303. DOI: 10.1002/psp.508.

Gridasov G.N., N.O. Zaharova, E.S. Balueva (2011). Sravnitel'nyy analiz dinamiki migratsionnogo prirosta pozhilogo naseleniya Samarskoy oblasti [A comparative analysis of the dynamics of migration growth of the elderly population of the Samara region] // Uspekhi gerontologii [Advances in gerontology]. 24. 4: 707-712.

Human Development Report 2009 (2009). Overcoming barriers: Human mobility and development. UNDP.

Jembreht R.V. (2011). Rol' obrazovatel'noy migratsii v demograficheskom razvitii Tomskoy oblasti (2000-2009 gg.) [The role of educational migration in the demographic development of the Tomsk Region (2000-2009)] // Vestnik Tomskogo gosudarstvennogo universiteta [Bulletin of the Tomsk state university]. 348: 76-79.

Kalogirou S. (2005). Examining and presenting trends of internal migration flows within England and Wales //Population, space and place. 11: 283-297. DOI: 10.1002/psp.376.

Kashnickij I.S., N.V. Mkrtchjan, O.V. Leshukov (2016). Mezhregional'naya migratsiya molodezhi v Rossii: kompleksnyy analiz demograficheskoy statistiki [Interregional migration of youth in Russia: complex analysis of demographic statistics] // Voprosy obrazovaniya [Educational studies]. 3: 169-203.

Kashnitsky I. S., N.V. Mkrtchyan (2014). Russian periphery is dying in movement: a cohort assessment of russian internal youth migration based on census data. NIDI working papers. 14.

Katrovskij A.P. (1999). Uchebnaya migratsiya v vuzy Rossii: faktory i motivatsiya // Migratsiya i urbanizatsiya $v$ SNG i Baltii v 90-e gody [Educational migration in higher education institutions of Russia: factors and motivation] // Migracija i urbanizacija v SNG i Baltii v 90e gody [Migration and urbanization in the CIS and the Baltic States in the 90th years] / Zh.A. 
Zajonchkovskaya, ed. Moscow: Sovet po migratsiyam stran SNG, Tsentr demografii i ekologii cheloveka: 269-276.

Little J., A. Rogers (2007). What can the age composition of a population tell us about the age composition of its out-migrants? // Population, space and place. 13: 23-29. DOI: $10.1002 / \mathrm{psp} .440$.

Mahrova A., T. Nefedova, A. Trejvish (2012). Moskva: megapolis? aglomeratsiya? megalopolis? [Moscow: megalopolis? agglomeration? megalopolis?] // Demoscope Weekly. 517-518. URL: http://demoscope.ru/weekly/2012/0517/demoscope517.pdf (accessed 02.10.2016).

Millington J. (2000). Migration and age: the effect of age on sensitivity to migration stimuli // Regional studies. 34 (6): 521-533.

Mkrtchjan N.V. (2011). Dinamika naseleniya regionov Rossii i rol' migratsii: kriticheskaya otsenka na osnove perepisey 2002 i $2010 \mathrm{gg}$. [The dynamics of the population of regions of Russia and the role of migration: a critical assessment on the basis of census 2002 and 2010] // Izvestiya RAN [Proceedings of the Russian academy of sciences]. Ser. Geografiya. 5: 2842.

Mkrtchyan N.V. (2013). Migratsiya molodezhi v regional'nye tsentry Rossii v kontse XX nachale XXI veka [The migration of youth in the regional centers of Russia at the end of XX - the beginning of XXIst century] // Izvestiya RAN [Proceedings of the Russian academy of sciences]. Ser. Geografiya. 6: 19-32.

Mkrtchyan N.V. (2014). O vliyanii migratsii na vozrastnoy sostav naseleniya regionov, gorodov i rayonov Rossii [The effect of migration on the age structure of the population of the regions, cities and districts of Russia] // Nauchnye trudy INP RAN [Scientific articles Institute of economic forecasting Russian academy of sciences]. Moscow: MAKS Press: 381 396.

Mkrtchyan N.V. (2015). Migratsiya v Moskve i Moskovskoy oblasti: regional'nye i strukturnye osobennosti [Migration in Moscow and the Moscow region: the regional and structural features] // Regional'nye issledovaniya [Regional studies]. 3: 107-116.

Moiseenko V. M., O.S. Chudinovskih (2000). Migratsionnye potoki pozhilogo naseleniya v Rossi [Migration flows of the elderly population in Russia] // Psikhologiya zrelosti i stareniya [Psychology of a maturity and aging]. 1: 28-35.

Naselenie Rossii 2001 [Population of Russia 2001] (2002). Devyatyy ezhegodnyy demograficheskiy doklad [The ninth annual demographic report] / A.G. Vishnevskij, ed. Moscow: KD «Universitet»: 47-50.

Naselenie Rossii 2012 [The population of Russia 2012] (2014). Dvadtsatyy ezhegodnyy demograficheskiy doklad [Ninth annual demographic report] / A.G. Vishnevskij, ed. Moscow: Izd. dom Vysshey shkoly ekonomiki: 309-317.

Pittenger D.B. (1974). A typology of age-specific net migration rate distributions // Journal of the American institute of planners. 40 (4): 278-283, DOI: 10.1080/01944367408977480.

Plane D., F. Heins (2003). Age articulation of U.S. inter-metropolitan migration flows // The annals of regional science. 37: 107-130.

Plane D., J. Jurjevich (2009). Ties that no longer bind? The patterns and repercussions of agearticulated migration // The professional geographer. 61(1): 4-20. DOI: $10.1080 / 00330120802577558$. 
Rahmanova G. (1994). Vozrastnye profili migratsii v Rossii i ee regionakh: 80-e i nachalo 90-kh gg. [The age profiles of migration in Russia and its regions: the 80th and the beginning of the 90th] // Migratsionnye protsessy posle raspada SSSR. Programma po issledovaniyu migratsii [Migratory processes after the collapse of the USSR. Program for a migration research]. Vyp. V / Zh.A. Zajonchkovskaja, ed. Moscow: 82- 113.

Rogers A., L. Castro (1981). Model migration schedules // Research report RR-81-30, IIASA, Laxenburg, Austria.

Rogers A., L. Castro (1986). Migration // Migration and settlement. A multiregional comparative study / Rogers A. and F. Willekens, eds. Dordrecht: Reidel Publ.: 157-208.

Smith P. W. F., J. Raymer, G. Corrado (2010). Combining available migration data in England to study economic activity flows over time // Journal of the royal statistical society. 173 (4): $733-753$.

Swiaczny F., Ph. Graze, C. Schloemer (2008). Spatial Impacts of demographic change in Germany - urban population processes reconsidered // Zeitschrift für Bevőlkerungswissenschaft. 33 (2):181-206.

Tarasova E.V. (2013). Osobennosti migratsii naseleniya starshe trudosposobnogo vozrasta $v$ Altayskom krae [Features of migration over the working age population in the Altai Territory] // Sotsial'naya integratsiya i razvitie etnokul'tur v Evraziyskom [Social integration and development of ethnocultures in Euroasian space]. 1: 150-153.

Varshavskaja E.Ja., O.S. Chudinovskih (2014). Migratsionnye plany vypusknikov regional'nykh vuzov Rossii [Migration plans of graduates of regional higher education institutions of Russia] // Vestnik Moskovskogo universiteta [Bulletin of the Moscow university]. Ser. 6: Ekonomika. 3: 36-58.

Wilson T. (2010). Model migration schedules incorporating student migration peaks // Demographic research. 23: 191-222.

Zaharov S.V., Ivanova E.I. (1996). Regional'naya differentsiatsiya rozhdaemosti v Rossii: 1959 1994 [Regional differentiation of birth rate in Russia: 1959 - 1994] // Problemy prognozirovaniya [Studies on Russian economic development]. 4: 109-130.

Zamjatina N.Ju. (2012). Metod izucheniya migratsiy molodezhi po dannym sotsial'nykh internetsetey: Tomskiy gosudarstvennyy universitet kak tsentr proizvodstva i raspredeleniya chelovecheskogo kapitala (po dannym sotsial'noy internet-seti VKontakte) [The method of studying the migration of young people according to online social networks: Tomsk State University as the center of production and distribution of human capital (according to the Internet social network VKontakte)] // Regional'nye issledovaniya [Regional studies]. 2: 1529.

Zamjatina N.Ju. (2014). Sotsial'naya lesotundra: geograficheskaya podvizhnost' kak element semeynykh traektoriy zhiteley severnykh gorodov (na primere Noril'ska i Dudinki) [Social forest-tundra: geographical mobility as an element of the family trajectories of the northern urban population (on the example of Norilsk and Dudinka)] // Neprikosnovennyy zapas [The NZ library]. 5 (97): 189-208. 